\title{
Change of Swallowing in Patients With Head and Neck Cancer After Concurrent Chemoradiotherapy
}

\author{
Sehi Kweon, $\mathrm{MD}^{1}$, Bon Seok Koo, $\mathrm{MD}, \mathrm{PhD}^{2}$, Sungju Jee, $\mathrm{MD}, \mathrm{PhD}^{1}$ \\ Departments of ${ }^{1}$ Rehabilitation Medicine, ${ }^{2}$ Otolaryngology-Head and Neck Surgery, \\ Chungnam National University Hospital, Daejeon, Korea
}

\begin{abstract}
Objective To evaluate the functional characteristics of swallowing and to analyze the parameters of dysphagia in head and neck cancer patients after concurrent chemoradiotherapy (CCRT).

Methods The medical records of 32 patients with head and neck cancer who were referred for a videofluoroscopic swallowing study from January 2012 to May 2015 were retrospectively reviewed. The patients were allocated by duration after starting CCRT into early phase ( $<1$ month after radiation therapy) and late phase ( $>1$ month after radiation therapy) groups. We measured the modified penetration aspiration scale (MPAS) and American SpeechLanguage-Hearing Association National Outcome Measurement System swallowing scale (ASHA-NOMS). The oral transit time (OTT), pharyngeal delay time (PDT), and pharyngeal transit time (PTT) were recorded to assess the swallowing physiology.

Results Among 32 cases, 18 cases (56\%) were of the early phase. In both groups, the most common tumor site was the hypopharynx (43.75\%) with a histologic type of squamous cell carcinoma (75\%). PTT was significantly longer in the late phase $(\mathrm{p}=0.03)$. With all types of boluses, except for soup, both phases showed a statistically significant difference in MPAS results. The mean ASHA-NOMS level for the early phase was $5.83 \pm 0.78$ and that for the late phase was $3.79 \pm 1.80$, with statistical significance $(\mathrm{p}=0.01)$. The PTT and ASHA-NOMS level showed a statistically significant correlation (correlation coefficient $=-0.52, \mathrm{p}=0.02$ ). However, it showed no relationship with the MPAS results.

Conclusion The results of our study suggest that in the late phase that after CCRT, the OTT, PDT, and PTT were longer than in the early phase and the PTT prolongation was statistically significant. Therefore, swallowing therapy targeting the pharyngeal phase is recommended after CCRT.
\end{abstract}

Keywords Deglutition disorders, Head and neck neoplasms, Chemoradiotherapy

Received February 22, 2016; Accepted June 13, 2016

Corresponding author: Sungju Jee

Department of Rehabilitation Medicine, Chungnam National University Hospital, 282 Munhwa-ro, Jung-gu, Daejeon 35015, Korea. Tel: +82-42-3382423, Fax: +82-42-338-2461, E-mail: drjeesungju@cnuh.co.kr

ORCID: Sehi Kweon (http://orcid.org/0000-0002-8745-9927); Bon seok Koo (http://orcid.org/0000-0003-3238-8719); Sungju Jee (http://orcid. org/0000-0002-9400-9609).

@ This is an open-access article distributed under the terms of the Creative Commons Attribution Non-Commercial License (http://creativecommons.org/ licenses/by-nc/4.0) which permits unrestricted noncommercial use, distribution, and reproduction in any medium, provided the original work is properly cited. Copyright $\odot 2016$ by Korean Academy of Rehabilitation Medicine 


\section{INTRODUCTION}

Head and neck cancer includes tumors involving the oral cavity, pharynx, and larynx, which are anatomical sites associated with the swallowing function. The main treatments for head and neck cancer patients (HNCPs) include surgery, radiation therapy, chemotherapy or a combination of these $[1,2]$. Adjuvant radiotherapy after surgery or exclusive radiotherapy, with or without concurrent chemotherapy, is a valuable treatment option in many patients with head and neck cancer $[3,4]$.

The advantage of undertaking radiation therapy is that it can preserve the muscle, nerve, bone and blood vessels. However, one of the common complications of radiotherapy is dysphagia, which alters the quality of life of patients [5]. Radiation-induced dysphagia is responsible for a change in the type of diet and a prolongation of the meal times, which participate in anorexia and malnutrition $[6,7]$. Also, severe dysphagia can lead to aspiration, and among HNCPs, the incidence of aspiration is estimated to be $36 \%-94 \%$ while the incidence of silent aspiration due to a decrease in the cough reflex is $22 \%-67 \%$ [8-10].

Radiation therapy is well known to induce fibrosis and neuropathy, which ultimately impair the swallowing mechanism and thus increase the risk of dysphagia [1113]. Some researchers have reported that after radiation therapy, the penetration and aspiration exhibited a statistically significant increase [14-16]. Videofluoroscopic analysis of the swallowing process after radiation therapy has revealed a decrease in pharyngeal peristalsis, defective posterior inversion of the base of the tongue, incomplete closure of the larynx, decreased inversion of the epiglottis, and delayed opening of the upper esophageal sphincter $[10,17,18]$. Murphy reported that these complications begin to show from 4 to 5 weeks after radiationbased therapy [19]. Due to mucositis, edema of the soft tissues, copious mucous production, xerostomia, and tissue swelling, patients begin to develop acute dysphagia. Later, fibrosis, lymphedema, and damage to neural structures occur, leading to the late effects of dysphagia [19].

However, to the best of our knowledge, these studies have only analyzed the results of the videofluoroscopic swallowing study (VFSS) in a quality active manner and have described the characteristics of impairment, so it is difficult to compare the swallowing function using mea- surable objective factors. Therefore, the aim of this study is to compare functional data after concurrent chemoradiotherapy (CCRT) and to analyze the change in swallowing function with respect to quantitative physiologic data.

\section{MATERIALS AND METHODS}

\section{Subjects}

We retrospectively reviewed the medical records of patients with head and neck cancer who had been referred from January 2012 to May 2015 for a VFSS. The inclusion criteria included those who (1) were diagnosed with head and neck cancer; (2) had undergone concurrent chemoradiotherapy; (3) were first referred for examination; (4) had full medical records; and (5) did not participate in swallowing therapy before VFSS. The exclusion criteria included (1) non-primary cancer; (2) recurrent cancer; and (3) insufficient medical records. A total of 86 patients were evaluated during the study period, and 54 patients were excluded according to the above criteria. Thus, the records of 32 patients were analyzed. All patients were allocated by duration after starting CCRT into an early phase ( $<1$ month after radiation therapy) or late phase ( $>1$ month after radiation therapy) group. The clinical characteristics consisted of patient (age, gender), cancer (TNM stage, date of diagnosis, histological type, location of cancer), and radiation therapy (date, dose) characteristics (Table 1). For the analysis, we compared the clinical characteristics, modified penetration aspiration scale (MPAS), the American Speech-Language-Hearing Association National Outcome Measurement System (ASHANOMS) level and swallowing physiologic data of both groups.

\section{Methods}

All patients underwent VFSS that were performed and recorded simultaneously (FLEXAVISION; Shimadzu Corp., Kyoto, Japan). Patients were seated upright on the fluoroscopy chair or wheelchair, and any patient who could not control his or her head independently used a reclined wheelchair. Then, each subject was asked to swallow 5 types of boluses: Yoplait, soup, $2.5 \mathrm{~mL}$ liquid, $5 \mathrm{~mL}$ liquid, and rice. During the entire test period, the sessions were simultaneously recorded as video files at 30 frames per second (INFINITT PACS video). The image was viewed in the lateral plane, which included the lips 
anteriorly to vertebrae posteriorly, and the soft palate superiorly to the sixth cervical vertebra inferiorly [20] (Fig. 1). Testing was discontinued if patients showed dyspnea, decrease in saturation, or unstable vital signs. A physiatrist with more than 5 years of experience performing swallowing studies analyzed the results after VFSS had been finished.

Table 1. Demographic and clinical characteristics

\begin{tabular}{|c|c|c|}
\hline Characteristic & Early phase & Late phase \\
\hline Age (yr) & $\begin{array}{l}65.50 \pm 11.66 \\
(33-86)\end{array}$ & $\begin{array}{l}59.86 \pm 7.34 \\
\quad(45-68)\end{array}$ \\
\hline \multicolumn{3}{|l|}{ Sex } \\
\hline Female & $2(11.11)$ & $2(14.29)$ \\
\hline Male & 16 (88.89) & $12(85.71)$ \\
\hline \multicolumn{3}{|l|}{ Site } \\
\hline Oral cavity & $3(16.67)$ & $3(21.43)$ \\
\hline Nasopharynx & $2(11.11)$ & $3(21.43)$ \\
\hline Oropharynx & $0(0)$ & $3(21.43)$ \\
\hline Hypopharynx & $10(55.56)$ & $4(28.57)$ \\
\hline Larynx & $3(16.67)$ & $1(7.14)$ \\
\hline \multicolumn{3}{|l|}{ Histology } \\
\hline Squamous & 15 (83.33) & $9(64.29)$ \\
\hline Non-keratizing & $2(11.11)$ & $2(14.29)$ \\
\hline Atypical & $0(0)$ & $1(7.14)$ \\
\hline Other & $1(5.56)$ & $2(14.29)$ \\
\hline $\begin{array}{l}\text { Dose of } \\
\text { radiation (cGy) }\end{array}$ & $\begin{array}{c}5,651.78 \pm 2,139.92 \\
(1,350-6,900)\end{array}$ & $\begin{array}{c}5,823.33 \pm 1,837.98 \\
(1,440-6,750)\end{array}$ \\
\hline
\end{tabular}

Values are presented as median \pm standard deviation (minimum-maximum) or number (\%).

\section{Swallowing physiology}

After VFSS was finished, a physiatrist reviewed the recorded video file without knowing to which group each case had been allocated. The physiatrist counted the number of frames and divided it by 30 , and then data was collected as time (seconds) taken during each phase of swallowing [7].

(1) The oral transit time (OTT) was defined as the length of time it takes the bolus to move through the oral cavity from the first frame showing backward movement of the food until the bolus head or tail passes a landmark in the posterior oral cavity.

(2) The pharyngeal transit time (PTT) was defined as the time it takes the bolus to move through the pharynx from the point at which the bolus head passes the back of the tongue or the ramus of the mandible until the bolus tail passes through the cricopharyngeal region, located behind the cricoid cartilage, approximately $1 \mathrm{~cm}$ below the true vocal folds.

(3) The pharyngeal delay time (PDT) is a component of the PTT, defined as the time from the bolus head arrival at the point where the shadow of the lower edge of the mandible crosses the tongue base until the pharyngeal swallow is triggered.

\section{Functional measurement of swallow}

After the VFSS, the results were assessed by obtaining the MPAS and ASHA-NOMS swallowing tests. The MPAS consists of a 5 -point scale, ranging from 1 to 5 as follows: 1 , material does not enter the airway; 2 , material enters the airway, remains above the vocal folds; 3 , material enters the airway, contacts the vocal folds; 4 , material enters the airway, passes below the vocal folds and effort is

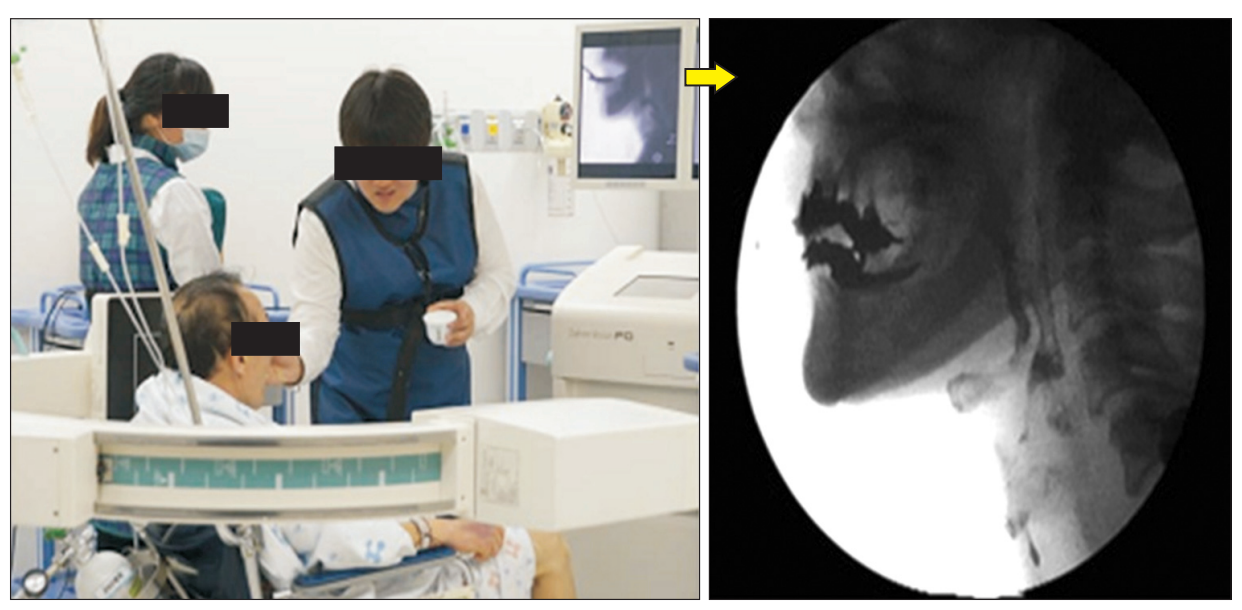

Fig. 1. Videofluoroscopic swallowing study lateral plane view. Each image included the lips anteriorly to the vertebrae posteriorly, and the soft palate superiorly to the 6 th cervical vertebra inferiorly. 
made to eject; 5 , material enters the airway, passes below the vocal folds and no effort is made to eject. The ASHANOMS scales are listed in Table 2 [21].

\section{Statistical analysis}

All of the baseline demographic and clinical data between two groups were analyzed using a Pearson chisquare test for categorical variables and an independent t-test for continuous variables. The differences were considered to be statistically significant at $\mathrm{p}<0.05$, and the

Table 2. The American Speech-Language-Hearing Association National Outcome Measurement System (ASHANOMS) swallowing scale

\begin{tabular}{|c|c|}
\hline Level & Description \\
\hline 1 & $\begin{array}{l}\text { Individual is not able to swallow anything safely } \\
\text { by mouth. All nutrition and hydration is } \\
\text { received through non-oral means. }\end{array}$ \\
\hline 2 & $\begin{array}{l}\text { Individual is not able to swallow safely by mouth } \\
\text { for nutrition and hydration, but may take some } \\
\text { consistency with consistent maximal cues in } \\
\text { therapy only. Alternative method of feeding is } \\
\text { required. }\end{array}$ \\
\hline 3 & $\begin{array}{l}\text { Alternative method of feeding required as } \\
\text { individual takes less than } 50 \% \text { of nutrition and } \\
\text { hydration by mouth, and/or swallowing is safe } \\
\text { with consistent use of moderate cues to use } \\
\text { compensatory strategies and/or requires } \\
\text { maximum diet restrictions. }\end{array}$ \\
\hline 4 & $\begin{array}{l}\text { Swallowing is safe but usually requires moderate } \\
\text { cues to use compensatory strategies, and/or } \\
\text { individual has moderate diet restrictions } \\
\text { and/or still requires tube feedings and/or oral } \\
\text { supplements. }\end{array}$ \\
\hline 5 & $\begin{array}{l}\text { Swallow is safe with minimal diet restrictions } \\
\text { and/or occasionally requires minimal cueing to } \\
\text { use compensatory strategies. May occasionally } \\
\text { self cue. All nutrition and hydration needs are } \\
\text { met by mouth at mealtime. }\end{array}$ \\
\hline 6 & $\begin{array}{l}\text { Swallowing is safe and individual eats and drinks } \\
\text { independently and may rarely require minimal } \\
\text { cueing. Usually self cues when difficulty occurs. } \\
\text { May need to avoid specific food items (e.g., } \\
\text { popcorn and nuts), or requires additional time } \\
\text { (due to dysphagia). }\end{array}$ \\
\hline 7 & $\begin{array}{l}\text { Individual's ability to eat independently is not } \\
\text { limited by swallow function. Swallowing would } \\
\text { be safe and efficient for all consistencies. } \\
\text { Compensatory strategies are effectively used } \\
\text { when needed. }\end{array}$ \\
\hline
\end{tabular}

Pearson correlation tests were used to determine whether the functional parameters were statistically correlated with the swallowing physiology. All statistical analyses were performed using the SPSS ver. 22.0 software (IBM Company, Armonk, NY, USA).

\section{RESULTS}

\section{Demographics and clinical characteristics}

A total of 32 medical records were reviewed. 18 patients were determined to belong to the early phase and 14 patients to the late phase. In the early status group, the average age was $65.50 \pm 11.66$ years with 16 males and 2 females in the population and an average period after radiation therapy of $8 \pm 8.73$ days. In late status group, the average age was $59.86 \pm 7.34$ years with 12 males and 2 females in the population and an average period after radiation therapy of $153 \pm 132.66$ days. In both phases, the most common tumor site was the hypopharynx (43.75\%). Histologically the most common type was squamous cell carcinoma (75\%). The baseline demographic information is described in Table 1, and there were no statistically significant differences between both groups for all demographic and clinical parameters ( $p>0.05)$.

\section{Swallowing physiology}

(1) Oral transit time: The mean OTT for the early phase was $1.47 \pm 0.70$ seconds and for the late phase was $1.53 \pm 0.35$ seconds. Although there was no statistically significant difference $(\mathrm{p}=0.76)$, the late phase had a tendency for a longer OTT.

(2) Pharyngeal transit time: The mean PTT for the early phase was $1.52 \pm 0.21$ seconds and for the late phase was $1.83 \pm 0.56$ seconds. The PTT was longer in late phase with statistical significance $(\mathrm{p}=0.03)$.

(3) Pharyngeal delay time: The mean PDT for the early phase was $1.17 \pm 0.11$ seconds and for the late phase was $1.28 \pm 0.25$ seconds. Although there was no statistically significant difference $(\mathrm{p}=0.10)$, the late phase had a tendency for a longer PDT.

A quantitative analysis of the swallowing physiology showed that the HNCPs exhibited a significant delay in the pharyngeal transit time after the CCRT during the late phase (Fig. 2). 


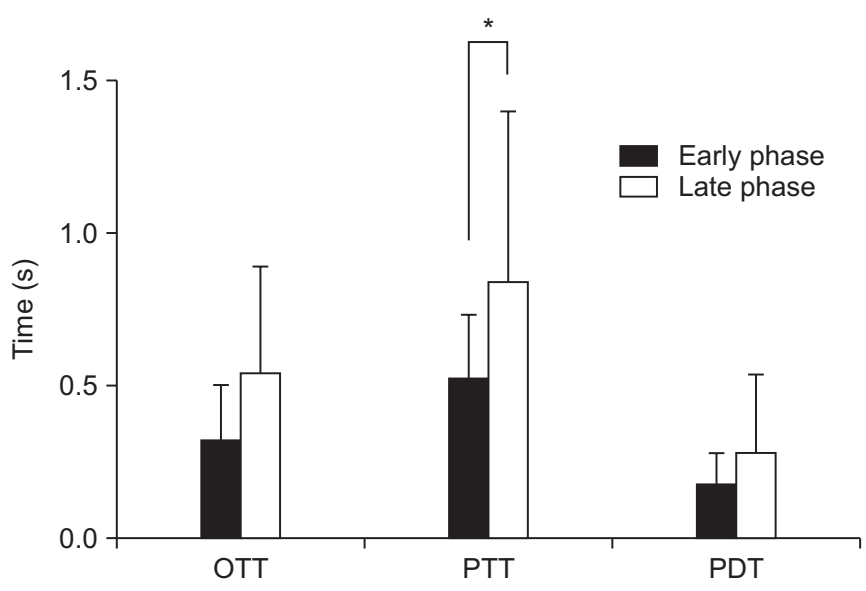

Fig. 2. Quantitative data of the swallowing physiology. People in the late status group showed a tendency for longer oral transit time (OTT) and pharyngeal delay time (PDT) than those in the early status group. Pharyngeal transit time (PTT) was statistically longer in the late status group $\left({ }^{*} \mathrm{p}<0.05\right)$.

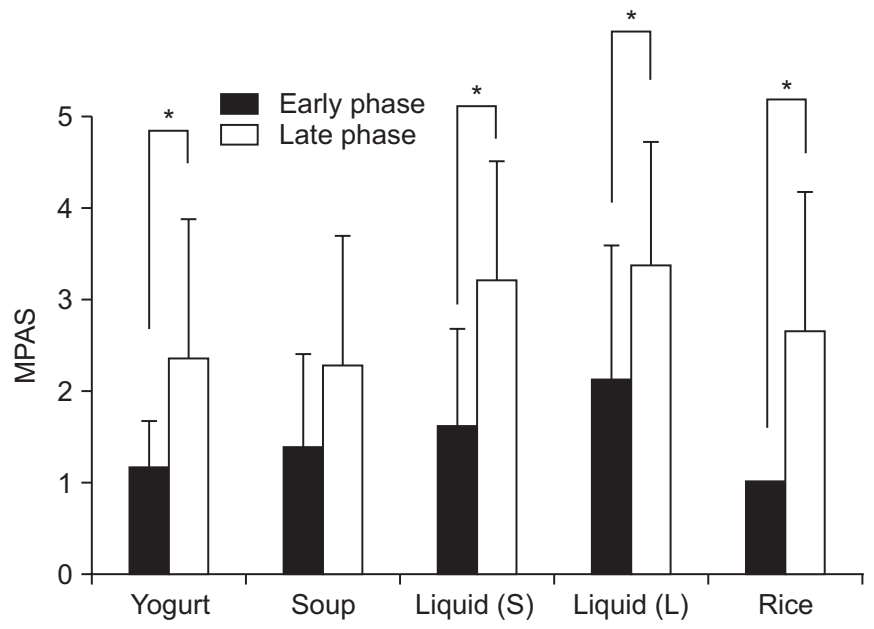

Fig. 3. Modified penetration aspiration scale (MPAS) for 5 different boluses between 2 phases. In all type of boluses, except soup, both groups showed a statistically significant difference in the MPAS results. That is, the late phase MPAS results were higher than those of the early phase.

\section{Functional measurement of swallow}

In early phase, no patient showed penetration or aspiration. However, in the late phase, 6 (42.8\%) patients showed penetration or aspiration.

The mean MPAS of Yogurt was 1.17 for the early phase and 2.36 for the late phase ( $\mathrm{p}=0.014)$. The MPAS of soup for the early and late phase were 1.39 and $2.29(\mathrm{p}=0.06)$, respectively. The MPAS of liquid $(2.5 \mathrm{~mL})$ were 1.61 and $3.21(\mathrm{p}=0.01)$, respectively. In all types of boluses, except
Table 3. Relationship between functional factors and PTT in late phase

\begin{tabular}{lcc}
\hline & $\begin{array}{c}\text { Pearson correlation } \\
\text { coefficient }\end{array}$ & p-value \\
\hline MPAS & 0.146 & 0.42 \\
Yogurt & 0.316 & 0.07 \\
Soup & 0.220 & 0.22 \\
Liquid 2.5 mL & 0.112 & 0.54 \\
\hline Liquid 5 mL & 0.331 & 0.06 \\
\hline Rice & -0.524 & $0.002^{*}$ \\
\hline ASHA-NOMS &
\end{tabular}

PTT, pharyngeal transit time; MPAS, modified penetration aspiration scale; ASHA-NOMS, American SpeechLanguage-Hearing Association National Outcome Measurement.

${ }^{*} \mathrm{p}<0.05$.

for soup, both groups showed a statistically significant difference in MPAS results, that is, the results of the latephase MPAS were higher than those for the early phase (Fig. 3).

The mean ASHA-NOMS level for the early phase was $5.83 \pm 0.78$ and for the late phase was $3.79 \pm 1.80$, with a statistically significant difference $(\mathrm{p}=0.01)$.

\section{Relationship between functional factors and PTT in late phase}

Pearson correlation tests were used to determine whether the MPAS of each bolus or ASHA-NOMS level were statistically correlated with PTT, which was statistically delayed in the late phase. The correlation coefficient showed a statistically significant correlation with ASHANOMS level (correlation coefficient $=-0.52, p=0.02$ ) (Table 3 ). However, it showed no relationship with MPAS for each of the boluses.

\section{DISCUSSION}

In this study, we quantitatively investigated the change in swallowing after CCRT for HNCPs. In the early phase, all patients did not show any aspiration. However, 6 people $(42.86 \%)$ showed aspiration or penetration in the late phase. For the swallowing physiology, people in the late phase showed a tendency for a longer OTT and PDT than in the early phase. The PTT showed a significant delay in the late phase.

Recently, the preservation of the swallowing function 
has been reported to be important as an oncologic cure for head and neck cancer treatment [22]. Radiotherapy and chemoradiotherapy offer high rates of locoregional control with good potential for functional organ preservation. However, the radiosensitized effect of chemotherapy is known to possibly lead to acute toxicity and late complications [23]. An inflammatory reaction and the production of reactive oxygen species after CCRT can cause dysphasia [24,25], and patients show acute dysphagia within 4 to 5 weeks of starting therapy. As the acute effects are resolved, late effects including fibrosis, lymphedema, and damage to neural structures rea then manifested [26].

Many studies have reported changes in swallowing function after chemoradiotherapy. Kotz et al. [18] followed 12 patients with stage III or IV squamous cell carcinoma of the head and neck cancer and showed that swallowing dysfunction is a common side effect of chemoradiation. However, the study was conducted with a small sample size, and the VFSS results were only analyzed in a qualitative manner. Katherine found late dysphagia after a radiotherapy-based treatment of head and neck cancer [22]. They analyzed 29 patients who were previously treated with radiotherapy, but they only analyzed the MPAS results. Nguyen et al. [14] retrospectively reviewed the Modified Barium Swallow in 63 patients who underwent concurrent chemoradiotherapy for head and neck cancer. However, they only categorized patients on a scale from 1 to 7 , lacking a description of the phase of swallowing that had been impaired.

In this study, we tried to quantitatively determine the change in swallowing function after CCRT using physiologic and functional data. Dysphagia was more prevalent in late phase after CCRT than in the early phase. This is consistent with observations from previous studies $[18,22]$. Regarding swallowing physiology, most patients with dysphagia showed a problem in the pharyngeal phase. We evaluated a quantitative comparison between the early phase and late phase after CCRT, not just comparing the qualitative characteristics. Our study showed that late phase PTT was significantly longer than for the early phase.

We also evaluated the functional measurement. In all types of boluses, except for soup, both groups showed a statistically significant difference in MPAS results. The risk of aspiration or penetration is known to vary accord- ing to the various types of food consistencies [27]. Soup has a low risk of aspiration or penetration, so it showed no significant difference between both groups.

Until now, CCRT is reported to induce dysphagia, but by just using ASHA-NOMS and MPAS, it is hard to know in which phase of swallowing the patient has a problem. A quantitative analysis of the swallowing physiology indicates that the HNCPs after CCRT have problem mainly in the pharyngeal phase. Therefore, this can imply that when doing swallowing therapy, exercises and maneuvers targeting the pharyngeal phase will be more effective than others. Furthermore, a follow-up evaluation of PTT after rehabilitation is recommended.

PTT showed no relationship with MPAS, but it was correlated with the ASHA-NOMS level. This may be explained by reviewing the swallowing process for which each dysphagia scale focuses on. MPAS is a scale that evaluates aspiration or penetration, and it focuses on whether there is penetration into the airway. However, the pharyngeal transit time, which showed statistical significance in this study, focuses on the bolus passage to the pharynx rather than the airway. The ASHANOMS level evaluates the overall bolus passage through the airway and the pharynx and allows for a decision for the further feeding route (oral or non-oral). Therefore, this may explain the relationship between the PTT and ASHA-NOMS level. Still, it seems that using only one of the scales (MPAS, ASHA-NOMS, swallowing physiology) is limited in being able to fully evaluate the swallowing of the patient. In summary, a comprehensive assessment is needed before planning the treatment maneuver.

The limitations of this study include its retrospective nature, absence of data regarding quality of life, and lack of long-term follow-up. In addition, our study did not compare the same patient in the early phase and late phase, but rather compared each of the cases of different phases. This can limit selection bias, and a future study comparing the swallowing physiology in the same patient at different times is needed. Finally, our study sample size was somewhat small.

In conclusion, the result of our study suggests that as more time passed after CCRT, the patient showed a delay in OTT, PDT, PTT, and this delay was statistically significant in PTT. Therefore, CCRT induced dysphagia mainly affects the pharyngeal phase during swallowing physiology, and swallowing therapy focusing on the pharyngeal 
phase is recommended. Additional prospective studies with long-term follow-up of same patients are needed to assess the change in swallowing in HNCPs after CCRT. Also, the change in function following rehabilitative management is needed to clarify the effect of rehabilitation training for the swallowing function.

\section{CONFLICT OF INTEREST}

No potential conflict of interest relevant to this article was reported.

\section{ACKNOWLEDGMENTS}

This study was supported by a grant from the National Research Foundation of Korea (NRF) funded by the Ministry of Science, ICT \& Future Planning (2015R1C1A1A01055923), Korean Health Technology R\&D Project (HI10C2020, HI3C1990), Ministry of Health $\&$ Welfare.

\section{REFERENCES}

1. Parsons JT, Mendenhall WM, Million RR, Stringer SP, Cassisi NJ. The management of primary cancers of the oropharynx: combined treatment or irradiation alone? Semin Radiat Oncol 1992;2:142-8.

2. Langendijk JA, Doornaert P, Verdonck-de Leeuw IM, Leemans CR, Aaronson NK, Slotman BJ. Impact of late treatment-related toxicity on quality of life among patients with head and neck cancer treated with radiotherapy. J Clin Oncol 2008;26:3770-6.

3. Kao J, Lavaf A, Teng MS, Huang D, Genden EM. Adjuvant radiotherapy and survival for patients with nodepositive head and neck cancer: an analysis by primary site and nodal stage. Int J Radiat Oncol Biol Phys 2008;71:362-70.

4. Lavaf A, Genden EM, Cesaretti JA, Packer S, Kao J. Adjuvant radiotherapy improves overall survival for patients with lymph node-positive head and neck squamous cell carcinoma. Cancer 2008;112:535-43.

5. Epstein JB, Robertson M, Emerton S, Phillips N, Stevenson-Moore P. Quality of life and oral function in patients treated with radiation therapy for head and neck cancer. Head Neck 2001;23:389-98.

6. Rosenthal DI, Lewin JS, Eisbruch A. Prevention and treatment of dysphagia and aspiration after chemoradiation for head and neck cancer. J Clin Oncol 2006;24:2636-43.

7. Rademaker AW, Vonesh EF, Logemann JA, Pauloski BR, Liu D, Lazarus CL, et al. Eating ability in head and neck cancer patients after treatment with chemoradiation: a 12-month follow-up study accounting for dropout. Head Neck 2003;25:1034-41.

8. Caudell JJ, Schaner PE, Meredith RF, Locher JL, Nabell LM, Carroll WR, et al. Factors associated with longterm dysphagia after definitive radiotherapy for locally advanced head-and-neck cancer. Int J Radiat Oncol Biol Phys 2009;73:410-5.

9. Garcia-Peris P, Paron L, Velasco C, de la Cuerda C, Camblor M, Breton I, et al. Long-term prevalence of oropharyngeal dysphagia in head and neck cancer patients: impact on quality of life. Clin Nutr 2007;26:710-7.

10. Eisbruch A, Lyden T, Bradford CR, Dawson LA, Haxer MJ, Miller AE, et al. Objective assessment of swallowing dysfunction and aspiration after radiation concurrent with chemotherapy for head-and-neck cancer. Int J Radiat Oncol Biol Phys 2002;53:23-8.

11. Dysphagia Section, Oral Care Study Group, Multinational Association of Supportive Care in Cancer (MASCC)/International Society of Oral Oncology (ISOO), Raber-Durlacher JE, Brennan MT, Verdonck-de Leeuw IM, et al. Swallowing dysfunction in cancer patients. Support Care Cancer 2012;20:433-43.

12. Delanian S, Lefaix JL, Pradat PF. Radiation-induced neuropathy in cancer survivors. Radiother Oncol 2012;105:273-82.

13. Jensen K, Lambertsen K, Grau C. Late swallowing dysfunction and dysphagia after radiotherapy for pharynx cancer: frequency, intensity and correlation with dose and volume parameters. Radiother Oncol 2007;85:7482.

14. Nguyen NP, Frank C, Moltz CC, Vos P, Smith HJ, Bhamidipati PV, et al. Aspiration rate following chemoradiation for head and neck cancer: an underreported occurrence. Radiother Oncol 2006;80:302-6.

15. Lazarus CL, Logemann JA, Pauloski BR, Colangelo LA, Kahrilas PJ, Mittal BB, et al. Swallowing disorders in head and neck cancer patients treated with radiotherapy and adjuvant chemotherapy. Laryngoscope 1996;106(9 Pt 1):1157-66.

16. Nguyen NP, Moltz CC, Frank C, Vos P, Smith HJ, Karls- 
son U, et al. Dysphagia following chemoradiation for locally advanced head and neck cancer. Ann Oncol 2004;15:383-8.

17. Eisbruch A, Schwartz M, Rasch C, Vineberg K, Damen E, Van As CJ, et al. Dysphagia and aspiration after chemoradiotherapy for head-and-neck cancer: which anatomic structures are affected and can they be spared by IMRT? Int J Radiat Oncol Biol Phys 2004; 60:1425-39.

18. Kotz T, Costello R, Li Y, Posner MR. Swallowing dysfunction after chemoradiation for advanced squamous cell carcinoma of the head and neck. Head Neck 2004;26:365-72.

19. Murphy BA. Clinical and economic consequences of mucositis induced by chemotherapy and/or radiation therapy. J Support Oncol 2007;5(9 Suppl 4):13-21.

20. Terk AR, Leder SB, Burrell MI. Hyoid bone and laryngeal movement dependent upon presence of a tracheotomy tube. Dysphagia 2007;22:89-93.

21. Mullen R, Schooling T. The National Outcomes Measurement System for pediatric speech-language pathology. Lang Speech Hear Serv Sch 2010;41:44-60.

22. Hutcheson KA, Lewin JS, Barringer DA, Lisec A, Gunn $\mathrm{GB}$, Moore MW, et al. Late dysphagia after radiother- apy-based treatment of head and neck cancer. Cancer 2012;118:5793-9.

23. Nguyen NP, Sallah S. Combined chemotherapy and radiation in the treatment of locally advanced head and neck cancers. In Vivo 2000;14:35-9.

24. Logemann JA, Rademaker AW, Pauloski BR, Lazarus CL, Mittal BB, Brockstein B, et al. Site of disease and treatment protocol as correlates of swallowing function in patients with head and neck cancer treated with chemoradiation. Head Neck 2006;28:64-73.

25. Sonis ST, Elting LS, Keefe D, Peterson DE, Schubert M, Hauer-Jensen M, et al. Perspectives on cancer therapy-induced mucosal injury: pathogenesis, measurement, epidemiology, and consequences for patients. Cancer 2004;100(9 Suppl):1995-2025.

26. Murphy BA, Gilbert J. Dysphagia in head and neck cancer patients treated with radiation: assessment, sequelae, and rehabilitation. Semin Radiat Oncol 2009; 19:35-42.

27. Ozaki K, Kagaya H, Yokoyama M, Saitoh E, Okada S, Gonzalez-Fernandez M, et al. The risk of penetration or aspiration during videofluoroscopic examination of swallowing varies depending on food types. Tohoku J Exp Med 2010;220:41-6. 